\title{
SUNAT PADA BAYI PEREMPUAN OLEH TENAGA TRADISIONAL
}

\author{
Nikmatur Rohmah ${ }^{1}$, Sofia Rhosma Dewi ${ }^{2}$, Susi Wahyuning Asih ${ }^{3}$, Saiful Walid ${ }^{4}$ \\ Fakultas Ilmu Kesehatan Univ. Muhammadiyah Jember ${ }^{1,2,3}$ \\ RSU dr H. Koesnadi Bondowoso ${ }^{4}$ \\ Email: r_nikmatur@yahoo.co.id
}

\begin{abstract}
Since 2005, Indonesia has been issued by the decision that female circumcision does not have any scientific basis and tends to be based on local tradition/culture. Female circumcision brings more adverse effects than its benefits (Juliansyah, 2009). This study aims to explain the phenomenon of female circumcision performed by traditional birth attendants. The research design of phenomenology was conducted in Bandilan hamlet of Arjasa village, Kendal hamlet of Kamal village, Arjasa subdistrict and Wetangunung hamlet of Wonojati village, Jenggawah subdistrict of Jember. The informants involved one traditional birth attendant for circumcision, 12 informants selected by using purposive sampling. The data were collected through interviews and observations. The validity test of the data was conducted by testing the credibility of triangulation. The data were then analyzed using analysis of interwoven and interactive analysis. These research emerging five themes. First theme is the reason why the baby circumcised, the second theme is baby girl circumcision is done by traditional bith attendant through special ritual, the third theme is circumcision equipment, the fourth theme is the procession, and the fifth theme is the baby response when she is being circumcised. Circumcision on baby girl performed by traditional birth attendants does not hurt the reproductive organs and does not eliminate the reproductive rights of women, the goal is to preserve and to maintain the local culture. It requires adequate education to straighten out the myths that is not true such as the infants will become infidels if they do not get the circumcision.
\end{abstract}

Keywords: Circumcision; Baby Girl; Traditional Birth Attendants

\section{PENDAHULUAN}

Penelitian yang dilakukan Population Council dengan Kementerian Pemberdayaan Perempuan mendapat data bahwa sunat pada perempuan atau disebut Female Genital Mutilation (selanjutnya disingkat FGM) selain dilakukan oleh tenaga tradisional juga dilakukan tenaga kesehatan dengan menggunakan peralatan jarum, pisau, dan gunting. Bentuknya irisan $22 \%$ dan eksisi/pengupasan $72 \%$. Penelitian lain menyenbutkan bahwa medikalisasi FGM yang dilakukan oleh tenaga kesehatan (terutama oleh bidan) cenderung dilakukan dengan cara yang lebih invasive (68-88\% kasus), dengan insisi atau eksisi yang lebih luas 
dibandingkan dengan yang dilakukan tenaga tradisional 43-67\% kasus (Juliansyah, 2009).

FGM terdiri dari 4 tipe, dimana tipe ini berkaitan dengan tingkatan kedalaman tindakan, mulai dari hanya insisi atau eksisi sebagian klitoris sampai dengan eksisi seluruh bagian genetalia eksterna (Juliansyah, 2009). Namun demikian sejak tahun 2005 di Indonesia telah sepakati bahwa FGM tidak memiliki landasan ilmiah dan lebih didasarkan pada tradisi dan budaya. Penelitian lain juga menyatakan bahwa medikalisasi FGM yang cenderung ke arah mutilasi lebih banyak membawa dampak buruk daripada manfaatnya (Juliansyah, 2009). Beberapa dampak yang dapat terjadi akibat FGM antara lain: nyeri berat, syok, perdarahan, tetanus, sepsis, retensi urine, ulserasi genital, dan infeksi (Ika, 2007). Dampak tersebut merupakan dampak jangka pendek yang dapat langsung terjadi beberapa saat setelah pelaksanaan FGM. Selain itu beberapa komplikasi jangka panjang juga dilaporkan terjadi antara lain: kista, abses, keloid, kerusakan uretra, inkontinensia urine, dispareni, disfungsi seksual akibat dispareni serta penurunan sensitivitas permanen akibat klitoridektomi dan infabulasi. Infabulasi juga mengakibatkan scar yang berat, kesulitan miksi, menstruasi, infeksi saluran kemih, serta kesulitan dalam hubungan seksual (Ika, 2007).

Hasil wawancara dengan ibu L. mengatakan bahwa "semua anak perempuan memang harus sunat, walaupun saya tidak tahu untuk apa? Adatnya memang begitu. Sunat perempuan itu ujung kelaminnya di gores dengan nyianyi/alat untuk memanen padi, tidak sampai mengeluarkan darah. Setiap anak perempuan yang sunat harus disediakan peras yang terdiri dari: beras, kelapa, bubuk kopi, gula, garam, bumbu dapur, jambe, daun siri, kapur, pinang, gambir, rokok, dan uang". Istilah yang digunakan untuk sunat anak perempuan adalah "aberse'en" dalam bahasa Madura yang diyakini dapat membersihkan kotoran yang keluar dari alat kelamin perempuan. Orang yang bisa melakukan sunnat biasanya dukun bayi kuno yang memang mempunyai keahlian untuk menyunat".

Sedangkan informan Ibu Y menyebutkan bahwa: "sunat pada bayi perempuan di desa Arjasa sudah lazim dilakukan dan hampir semua bayi perempuan pasti disunat karena ini merupakan ritual bagi seorang anak perempuan supaya dia menjadi anak yang baik. Berbagai benda harus disiapkan sebelum sunat yang biasa disebut peras dan nanti harus diberikan pada mbah dukun yang nyunat. Namun benda-benda yang berupa makanan pantang dimakan oleh dukun sunat, ia hanya boleh menerima tetapi tidak boleh memakan. Ibu Y meyakini bahwa sunat pada bayi perempuan tidak akan mendatangkan bahaya apapun".

Informan Ny. T juga menjelaskan bahwa "Semua anak perempuan itu harus disunat. Adatnya seperti itu. Alasan pastinya apa saya juga tidak tahu. Ikut budaya orang tua saja. Katanya supaya anaknya menjadi anak baik. Yang biasnya nyunat itu dukun bayi. Tapi karena sekarang jarang yang melahirkan ke dukun, jadi yang 
nyunat ya dukun yang merawat bayinya itu. Nyunatnya juga berbeda dengan lakilaki. Tidak dilukai, tapi hanya diusap dengan anyi-anyi”.

Sejauh ini memang tidak pernah ada laporan dari masyarakat Kecamatan Arjasa tentang dampak FGM, namun demikian bukan berarti dampak ini tidak terjadi. Hal ini kemungkinan karena faktor malu atau takut untuk mengungkapkan hal-hal yang berkaitan dengan reproduksi perempuan. Beberapa permasalahan yang dihadapi dalam FGM adalah bahwa dibeberapa daerah pelaksanaan FGM memang berupa menggoreskan alat sunat pada ujung klitoris, sehingga tidak cukup melukai atau menciderai anak perempuan. Tetapi di beberapa daerah yang lain di Indonesia melakukan insisi/ eksisi klitoris. Bahkan di Eropa FGM tipe 3 juga dilakukan. Dampak negatif dari FGM pada umumnya timbul akibat FGM tipe 1, 2, dan 3. Sedangkan FGM yang hanya simbolik tentu tidak menimbulkan dampak fisik yang berarti, bahkan justru memberikan sugesti bagi orangtua bahwa anaknya telah dibersihkan. Situasi ini menjadi dilema, bahwa melihat dampak negatifnya banyak pihak yang mengusulkan untuk meniadakan/ melarang sunat bagi perempuan, sementara bagi masyarakat yang melakukan sunat simbolik justru berupaya melestarikan adat sunat bagi perempuan. Fenomena ini mengindikasikan bahwa diperluka data dan fakta empiris yang mampu mengunkapkan sejauhmana pelaksanaan FGM di masyarakat, sehingga didapatkan pemikiran yang arif dan bijaksana terkait upaya larangan FGM. Selain itu juga bila FGM lebih menekankan adat atau tradisi maka perlu pemikiran yang bijak berkaitan dengan upaya melestarikan budaya lokal yang tidak merugikan kesehatan.

Berdarkan uraian diatas maka diperlukan penelitian mendalam berkaitan dengan sunat bagi perempuan di pedesaan yang mampu menggali kondisi riil bagaimanakah pelaksanaan FGM, sejauh mana FGM berdampak pada pemenuhan hak reproduksi perempuan? Sehingga masyarakat mempunyai perilaku yang tepat dalam menyikapi FGM.

Urgensi penelitian yang utama berkaitan dengan gencarnya upaya pemerintah dalam meningkatkan derajat kesehatan anak, khususnya aspek promotif. Yaitu meningkatkan dan mempertahankan kondisi anak yang sehat. Urgensi kedua bahwa adat atau tradisi dalam paradigm keperawatan anak merupakan salah satu bagian dari lingkungan yang dapat memengaruhi kesehatan. Keperawatan transkultural merekomendasikan bahwa budaya yang berpengaruh buruk pada kesehatan anak harus diminimalkan, budaya yang berpengaruh baik pada kesehatan anak harus ditingkatkan, serta dilestarikan, dan budaya yang tidak berpengaruh positif maupun negatif bagi kesehatan anak boleh dipertahankan. Urgensi ketiga berkaitan dengan prinsip holistic dalam keperawatan anak, bahwa perawatan kesehatan anak tidak hanya melihat aspek fisik, tetapi juga psikososial spiritual dan kultural. Karena masing-masing aspek akan terkait satu dengan yang lain dan merupakan kondisi yang saling memengaruhi. 


\section{METODE PENELITIAN}

Desain penelitian yang digunakan adalah fenomenologi. Penelitian dilakukan di dusun Bandilan Desa Arjasa, Dusun Kendal Desa Kamal Kecamatan Arjasa dan Dusun Wetangunung Desa Wonojati Kecamatan Jenggawah Kabupaten Jember. Pertimbangan lokasi penelitian karena di dusun Bandilan mayoritas masyarakat bersuku Madura dan berbahasa Madura, dan hampir semua anak perempuan dilakukan sunat semasa bayi. Tenaga tradisional untuk menyunat di dusun ini ada/tersedia. Waktu penelitian dilaksanakan selama 6 bulan mulai September 2015 sampai Januari 2016.

Populasi target adalah masyarakat pedesaan. Pemilihan informan didasarkan pada enkulturasi penuh dan keterlibatan langsung informan, rekruitmen informan dilakukan dengan pendekatan purposive sampling yakni sesuai dengan tujuan penelitian dan cukup representative. Jumlah partisipan yang diambil ditentukan oleh kualitas informasi yang diperoleh melalui proses wawancara dan tidak adanya informasi baru yang diperoleh. Pada penelitian ini yang menjadi nara sumber (informan) 13 informan yang terdiri dari 1 tenaga tradisional yang bisa menyunat bayi perempuan, dan 12 informan yang menyunatkan bayi perempuannya. Pengumpulan data melalui wawancara tidak terstruktur dan mendalam sekaligus observasi_terhadap informan dan observasi langsung pelaksanaan sunat bayi perempuan. Uji keterpercayaan data dilakukan dengan triangulasi sumber data.

Analisis data dilakukan dengan analisis jalinan \& Analisis Interaktif yaitu analisis interelasi yang dilakukan terus menerus sampai ditemukan hal yang mendalam atau meluas. Pelaksanaan analisis jalinan dan interaktif ini berlangsung secara bersamaan selama pengumpulan atau reduksi data, uji keterpercayaan data, dan analisis data.

\section{HASIL DAN PEMBAHASAN}

Hasil penelitian ini membuktikan bahwa praktek sunat pada perempuan yang dilakukan pada usia bayi masih terjadi di masyarakat pedesaan. Dua belas informan yang berasal dari tiga desa menyatakan seluruh keluarganya (perempuan) sunat (sonnat atau eberse'en dalam bahasa Madura). Temuan ini mendukung penelitian Penelitian Bjälkander et all. (2012) yang dilakukan di Sierra Leone menunjukkan bahwa salah satu Negara tertinggi FGM di dunia adalah Sierra Leone. Penelitian dilakukan terhadap 258 perempuan yang dipilih secara acak dipilih. Hasil penelitian menunjukkan bahwa semua responden telah menjalani FGM, kebanyakan antara umur 10 sampai 14 tahun.

WHO mendefinisikan FGM sebagai semua tindakan/prosedur yang meliputi pengangkatan sebagian atau total dari organ genitalia eksterna perempuan atau bentuk perlukaan lain terhadap organ genetalia perempuan dengan alasan budaya, atau alasan nonmedis lainnya, tetapi tidak termasuk tindakan bedah transeksual 
(Juliansyah, 2009). Sunat perempuan, dikenal juga dengan istilah sirkumsisi atau khitan perempuan. Sedangkan istilah secara internasional sunat perempuan adalah Female Genital Mutilation (FGM) atau Female Genital Cutting (FGC). Penggunaan istilah sendiri masih seringkali diperdebatkan (Ika, 2007).

Penelitian yang dilakukan oleh Ezenyeaku, Okeke, Chigbu, dan Ikeako. (2011) di Nigeria mendapatkan fakta bahwa banyak perempuan yang menjalani FGM mendapatkan bahaya dan komplikasinya. Prevalensi FGM adalah 42,1\%. Namun, hanya $14,3 \%$ dari responden menunjukkan kesediaan untuk menyunat anak perempuan mereka sendiri hal ini menunjukkan pengurangan yang signifikan pada pelaksanaan FGM. Sebagian besar $(63,7 \%)$ responden mendukung undang-undang menentang FGM.

Beberapa faktor yang mendorong orangtua untuk menyunatkan bayi perempuan yang muncul dalam penelitian ini antara lain:

1. Tidak tahu, hanya ikut-ikutan orangtua

Tradisi atau kebiasaan masyarakat seringkali diwariskan secara turun temurun, dari generasi satu ke generasi berikutnya. Pewarisan tradisi semacam ini seringkali terjadi tanpa penolakan dan pertanyaan. Seluruh informan mengatakan bahwa sebenarnya ia tidak tahu kenapa anak perempuan harus disunat.

Ny. T mengatakan: "tak oneng na, gi norok cakna reng wa-tuwa, pon kabbi neka mon bini' meste esonat". Demikian pula Ny. Y mengatakan: "tak oneng gule, gi pokokna mon binik kodu eberse'en.

Muslihatun (2010) menyatakan bahwa proses pewarisan tradisi dari satu generasi ke generasi berikutnya melalui beberapa tiga cara, antara lain: (1) proses internalisasi, proses yang berlangsung sepanjang hidup individu, yaitu mulai dari lahir hingga akhit hayatnya. Sepanjang hayatnya seseorang terus belajar untuk mengolah segala perasaan, hasrat nafsu, dan emosi kemudian menjadi sebuah kepribadian. (2) proses sosialisasi, yaitu proses individu belajar berinteraksi dengan sesamanya dalam suatu masyarakat menurut sistem nilai, norma, dan adat istiadat yang mengatur masyarakat yang bersangkutan. (3) proses enkulturasi, yaitu proses belajar dan menyesuaikan alam pikiran serta sikap adat, sistem norma, serta semua aturan yang ada di dalam kebudaayaan suatu masyarakat.

Masyarakat madura merupakan masyarakat yang patuh dan taat pada ajaran agama dan adat istiadatnya. Ibu-ibu yang membawa bayi perempuannya sunat sudah menginternalisasi nilai bahwa sunat memang harus dilakukan tanpa harus mengetahui manfaatnya, dan juga bahayanya. Seperti yang disampaikan Ny. T :" kabbi mon bini' gi koduh esonat. Pon adetta. Anapa mak koduh esonat gi tak oneng bulle. Norok reng wa-tuwa. Cakne makle anak'en selamet".

Selama ini yang terjadi di masyarakat pedesaan belum pernah ada laporan bahwa dengan sunat akan timbul suatu keburukan. Hal ini dikarenakan sunat pada 
perempuan yang dilakukan di ketiga desa lebih mengarah pada sunat secara simbolik yang tidak menimbulkan perlukan. Hal ini berbeda dengan penelitian Amu, et all. (2012) bahwa dampak FGM dapat berupa pembengkakan vulva. Fenomena yang yang terjadi di masyarakat pedesaan justru sebaliknya apabila ditemukan perilaku yang buruk dilakukan oleh seorang perempuan masyarakat menduga bahwa mungkin perempuan tersebut tidak disunat. Misalnya perilaku ketidakmampuan dalam mengelola keuangan keluarga. Banyak masyarakat yang memberikan ungkapan bahwa seorang istri yang tidak mampu berhemat mengelola keuangan keluarga adalah perempuan yang tidak disunat.

2. Lazim/kebiasaan

Alasan kedua yang disampaikan informan adalah karena lazimnya atau kebiasaan masyarakat desa melakukan sunat pada perempuan semasa bayi. Sebanyak sembilan informan mengatakan bahwa sunat pada perempuan memang lazim dilakukan oleh orangtua. Ny. T mengatakan: "pon kaprana mon binik esonat". Tn S mengatakan: "kapra jet cakna oreng-oreng sepuh mon binik esonat". Empat informan mengatakan bahwa kebiasaan masyarakat di desa bayi perempuan harus disunat. "pon biasa kanje mon binik esonat, tak nyaman mon tak esonat".

WHO menyatakan bahwa salah satu alasan sunat adalah sosialogis. FGM merupakan tindakan melanjutkan tradisi, menghilangkan hambatan atau kesialan bawaan, masa peralihan pubertas atau wanita dewasa, perekat sosial, dan merasa lebih terhormat (Juliansyah, 2009). Martinelli dan Ollé-Goig. (2012) menyebutkan bahwa praktek FGM masih tersebar luas di 28 negara Afrika dan 98\% dari perempuan di Djibouti telah melakukan berbagai bentuk FGM.

Kelaziman atau kebiasaan bagi orang pedesaan mengandung makna bahwa masyarakat yang tidak mengikuti kebiasaan diberi label tidak lazim/ "tak kapprah". Bagi penduduk pedesaan tentu hal ini menjadi sulit untuk hidup diantara lingkungan yang mendukung sunat untuk tidak melakukan sunat. Predikat-predikat tertentu bagi masyarakat kadang-kadang dihargai lebih tinggi dari yang seharusnya. Banyak tindakan-tindakan yang irrasional sekalipun akan tetap dilakukan hanya untuk mempertahankan hubungan sosial. Sehingga sebagaimana alasan yang pertama, walaupun tidak tahu alasan dan manfaatnya tetapi karena lazim dilakukan maka dengan kesadaran dan kerelaan hati masyarakat tetap melakukannya.

Alasan ini juga berbeda dengan temuan Okwudili dan Chukwudi (2012) dalam sebuah studi kasus terhadap seorang gadis 23 tahun yang telah menjalani FGM mengalami gangguan perkemihan dan obstruksi jalan lahir dan memerlukan penanganan yang serius untuk mengatasinya. Hal ini menunjukkan bahwa FGM mempunyai dampak yang cukup serius dan memerlukan pendidikan kesehatan yang adekuat untuk mencegah FGM 
3. Syarat sebagai orang Islam

Faktor pendorong ketiga berhubungan dengan kesadaran beragama. Sebagai orang Islam mereka merasa ada anjuran untuk sunat, walaupun mereka tidak mampu menjelaskan dasar pelaksanaan kegiatan itu baik dari Al-Quran maupun Al-Hadits. Mereka juga tidak mampu menjelaskan dari kyai atau ustadz yang mana yang telah mengajarkan dan bagaimana isi dari pelajaran yang disampaikan.

Satu informan mengatakan bahwa "mon cakna oreng watuwa mon Islam lake binik sonat".

Zaharudin (2006) menjelaskan bahwa dalam sebuah hadits dijelaskan lima perkara fitrah: berkhitan, mencukur bulu kemaluan, memotong kuku, mencabut bulu ketiak (cukur), memendekkan misai (Riwayat Muslim). Pandangan para ulama dalam memahami hadits di atas terbagi atas tiga pendapat: (1) hukumnya "sunnah" baik bagi laki-laki maupun wanita. Ini adalah pandangan Imam Malik, Imam Abu Hanifah, dan sebagian ulamak madzhab Syafi'i. (2) hukumnya "wajib bagi lelaki dan wanita, demikian fatwa madzhab Syafie dan kebanyakan ulama. (3) hukumnya "wajib" bagi laki-laki, dan "sunnah" bagi wanita. Demikian pandangan sebagian ulama Syafi'i dan madzhab Hambali.

Berdasarkan uraian tadi tampak bahwa sebetulnya dalam pandangan Islam juga masih terjadi perbedaan. Namun demikian pandangan yang ketiga adalah yang paling netral dipandang dari sudut hak-hak reproduksi wanita apabila pelaksanaan FGM lebih ke arah menciderai salah satu bagian dari alat kelamin wanita.

4. Kepercayaan kalau tidak sunat dianggap kafir

Hasil penelitian ini juga mendapatkan data bahwa kalau tidak sunat berarti kafir. Walaupun kafir yang dimaksud disini bukan berarti keluar dari Islam. Tiga informan mengatakan "mon tak esonat kafer" akan tetapi ketiga informan tidak mampu menjelaskan yang dimaksud kafir dalam konteks ini apa? "Kaper gi kaper, tak oneng na pokok cakna watuwa geneka kodu sonat, mon tak sonat kaper”. Artinya kotor karena tidak dibuang. Sebagaimana orang laki-laki yang sunat. Pendapat yang menggunakan istilah agama yang cukup ekstrem ini tentu tidak dapat dibenarkan karena dalam arti bahasa kafir artinya orang yang menyembunyikan atau pengingkaran. Padahal dalam konteks ini istilah kafir digunakan untuk memberi tekanan agar masyarakat mau melaksanakan sunat.

5. Kepercayaan jika tidak disunat menyebakan keburukan, boros, tidak bisa awet jika memiliki rejeki

Juliansyah (2009) menyebutkan bahwa WHO juga mengidentifikasi bahwa salah satu alasan sunat adalah adanya mitos dapat meningkatkan kesuburan dan daya tahan anak. Penelitian ini mendapatkan mitos lain yaitu berkaitan dengan manjemen keuangan. Perempuan yang tidak sunat akan menjadi perempuan yang boros berapapun banyaknya rezki yang dia punya pasti tetap kurang "cakna 
reng watuwa mon tak esonat jubek" akan tetapi sama dengan istilah kafir mereka tidak mampu menjelaskan kejelekan dalam hal apa? "pokokna jubek, tak oneng geneka gi jubek cakna".

Mitos-mitos ini justru meningkatkan banyaknya praktek FGM. Mitos ini semakin berkembang karena tidak ada laporan berkaitan dengan efek negatif FGM baik yang ringan maupun yang berat. Fenomena ini juga berbeda dari temuan Gele, Bo, dan Sundby. yang meneliti di Somalia tahun 2013, menyatakan bahwa sunat perempuan merupakan masalah kesehatan masyarakat yang utama yang sebagian besar memberikan kontribusi untuk angka kesakitan perempuan dan anak-anak. Demikian juga temuan Dalal, Lawoko, dan Jansson. (2010) melakukan studi cross-sectional pada 9.159 wanita, untuk menguji sikap perempuan terhadap penghentian FGM dalam hubungan dengan akses mereka terhadap informasi, pendidikan kesehatan dan keyakinan terhadap budaya. Hasil penelitian mendapatkan bahwa keyakinan akan budaya mempengaruhi sikap perempuan terhadap FGM. Perempuan yang telah mendapatkan informasi yang memadai tentang bahaya FGM lebih mungkin mendukung penghentian FGM dibanding perempuan yang tidak tahu bahaya FGM.

Berdasarkan uraian diatas maka dapat diambil kesimpulan bahwa dalam pelaksanaan sunat pada bayi perempuan di masyarakat pedesaan berbeda hasilnya dengan temuan-temuan terdahulu. Penelitian ini menemukan tiga kondisi budaya sunat pada perempuan di masyarakat pedesaan berkaitan dengan kesehatan. Pertama budaya yang menguntungkan kesehatan, adapun budaya yang menguntungkan kesehatan adalah kepercayaan bahwa perempuan itu harus bersih "eberseen" kalau tidak bersih jelek "jubek". Kebersihan terutama di alat kelamin wanita sangat penting karena akan mengurangi risiko penyakit-penyakit infeksi di daerah alat kelamin dan menekan infeksi yang dapat memerantarai penyakit yang ditularkan pada bayi selama dalam kandungan dan saat proses persalinan. Budaya ini perlu dipertahankan, karena mengandung unsur dukungan, fasilitasi atau pengambilan keputusan yang memungkinkan seseorang menjadi sehat atau lebih sehat, sehingga ia mampu menolong dirinya sendiri dan menolong orang lain dalam suatu perilaku tertentu, khususnya yang berkaitan dengan kebersihan. Kebudayaan bersih ini tentu perlu dipertahankan dan seseorang perlu mempertahankan nilai perawatan menjadi bersih sehingga mereka dapat memperthanakan kesejahteraannya, pulih dari penyakit atau menghadapi rintangan mapun kematian.

Kedua, budaya yang merugikan kesehatan dan melanggar prinsip agama. Budaya yang merugikan adalah adanya kepercayaan bahwa kalau tidak sunat boros "tak serak rejekena" padahal boros berkaitan dengan kemampuan manajemen keuangan bukan sunat. Selain itu ada kepercayaan kalau tidak sunat kafir, padahal kafir menurut terminologi Islam adalah dalam bahasa Arab: kāfir; plural kuffār secara harfiah berarti orang yang menyembunyikan atau mengingkari kebenaran. Dalam terminologi kultural kata ini digunakan dalam agama Islam untuk merujuk 
kepada orang-orang yang mengingkari nikmat Allah (sebagai lawan dari kata syakir, yang berarti orang yang bersyukur. Jadi menurut syariat Islam, manusia kāfir yaitu: mengingkari Allah sebagai satu-satunya yang berhak disembah dan mengingkari Rasul Muhammad SAW sebagai utusan-Nya. Penggunaan istilah kafir menjadi tidak tepat karena sebenarnya tidak digunakan untuk mengkafirkan orang yang tidak sunat.

Budaya yang merugikan perlu dilakukan restrukturisasi. Perawatan transkultural mengacu pada seluruh bantuan, dukungan, fasilitas atau keputusan dan tindakan profesional yang dapat menolong klien untuk mengubah atau memodifikasi cara hidup mereka agar lebih baik dan memperoleh pola perawatan yang lebih menguntungkan dengan menghargai keyakinan dan nilai yang dimiliki klien sesuai dengan budayanya. Cultural shock akan dialami oleh klien saat perawat atau tenaga kesehatan tidak mampu beradaptasi dengan nilai budaya dan kepercayaan yang dianut oleh klien. Sehingga hal ini dapat menimbulkan ketidanyamanan dan ketidakberdayaan dalam proses pemberian perawatan.

Ketiga, budaya yang netral. Data tentang sunat pada perempuan yang netral ditunjukkan pada adanya ungkapan bahwa orang Islam syaratnya harus sunat. Keperawatan memandang bahwa budaya yang netral perlu dilakukan negoisasi atau akomodasi yang memungkinkan perawat menolong masyarakat sesuai dengan adaptasi kebudayaan mereka atau melakukan negosiasi dengan fihak lain untuk mencapai hasil kesehatan yang menguntungkan dan memuaskan melalui perawatan yang profesional.

Penelitian ini juga mendapatkan data bahwa tenaga tradisional yang melaksanakan sunat disebut dukun (dalam hal ini yang dimaksud adalah dukun sunat). Ada dua jenis: (1) Dukun yang menolong persalinan dan berasal dari belajar, dan (2) Dukun yang mempunyai keahlian dari "alamat"/ petunjuk. Waktu yang digunakan untuk melaksanakan sunat pada umumnya setelah upacara kelahiran bayi yang disebut sebagai upacara "molangare" yang dilaksanakan pada hari ke 25 , 40, 50, atau 70 hari setelah lahir. Penentuan harinya bebas termasuk juga jamnya.

Tenaga tradisional yang menjadi dukun sunat melalui "alamat" harus melalui proses tertentu. Hasil penelitian ini mendapatkan data sebagai berikut: Ibu M merupakan tiga bersaudara, suatu hari Ibu M bermimpi didatangi neneknya yang juga dukun beranak, disuruh memilih "mau bisa berjalan/ ajelen atau mau lumpuh" akhirnya Ibu M memilih bisa berjalan. Setelah itu puasa 41 hari, lamanya mulai imsyak sampai maghrib. Makanan sahur/berbuka hanya sayuran yang ditakar: kacang panjang 2 lonjor, labu siam 2 sisir dan minuman berasal dari air mentah. Larangan selama puasa antara lain: makanan yang mengandung garam, minyak, nasi, ikan, makanan atau minuman yang dimasak dan berasa serta kontak dengan api.

Setelah 41 hari berpuasa Ibu Membuat ketupat 7 biji dan dimakan tiap hari 1 biji, kemudian Ibu M bermimpi kembali di datangi neneknya yang menyampaikan 
bahwa: tetangganya yang sedang hamil tidak diperkenankan memanggil orang lain, cukup meminta tolong Ibu M. Setelah ada yang mau melahirkan meminta bantuan Ibu $\mathbf{M}$ tetapi Ibu $\mathbf{M}$ menolak karena merasa tidak tahu sama sekali tentang persalinan. Tetangganya memaksa untuk meminta bantuan sampai tiga kali. Sampai akhirnya Ibu M mau datang ke tetangga yang mau melahirkan, setelah tiba ditempat persalinan seolah-olah neneknya datang kemudian mengajarkan doa-doa ritual dan cara menolong persalinan/ melahirkan, memotong tali pusat, dan mengeluarkan ariari, sampai dengan perawatan masa nifas. Pelajaran cara menyunat juga diperoleh dengan cara yang sama melalui alamat yang datang tiba-tiba begitu ada bayi yang akan di sunat.

Ritual persiapan sebelum sunat pada bayi perempuan adalah sebagai berikut: pertama adalah persiapan untuk selamatan sunat, antara lain: Rasol (nasi diberi telur masak 1 biji). Tajin merah 2 takir dan 1 lepek, tajin putih 2 takir dan 1 lepek. Kue 7 macam (pisang goreng, kucur, gelung teleng, ketupat, lepet, “e'mbel”, roti), jumlah masing-masing kue terserah 1-5 yang penting jenisnya 7 macam, dan atau ditambah selamatan "tretan" (manisan, krupuk, ciki-ciki, kacang, biscuit, roti, kacang bawang). Bunga terserah jenis minimal 3 macam (mawar, kenanga, gading) dan banyaknya kira-kira 1 genggam, menyan sebesar seruas jari di letakkan di tengah bunga, ditambah uang sebagai "selabet", banyaknya terserah, Damar kambang, sejenis lilin terbuat dari tutup botol yang dilubangi kemudian di masukkan sumbu yang terbuat dari kapas kemudian diberi bahan bakar minyak goreng. Untuk penahan diberi sebuah kayu kecil sepanjang jari tengah yang bercabang kemudian lampu diletakkan diantara cabang kayu.

Kedua selamatan "molangare", antara lain: Peras: beras $1 \mathrm{~kg}$, gula secukupnya, dan bubuk kopi secukupnya untuk 1 gelas. Pelepa: kunyit, ketumbar, jahe,laos, daun jeruk, bawang daun, bawang merah, bawang putih, kemiri, merica (kadang-kadang), garam, vitsin. Kelapa dikupas kulitnya tinggal kelapa dengan tempurung, dililit bola putih atau bola kasur putih, kurang lebih seukuran lingkar perut bayi $\pm 50 \mathrm{~cm}$. Pisang apa saja jenisnya sebanyak 1 sisir. Bunga terserah jenis minimal 3 macam (mawar, kenanga, gading) dan banyaknya kira-kira 1 genggam, kemenyan sebesar seruas jari di letakkan di tengah bunga, ditambah uang sebagai selabet, banyaknya terserah.diletakkan di atas peras. Rokok satu buah. Uang sebagai sari/selamat banyaknya terserah paling sedikit Rp 1000,- Nasi tumpeng, ayam kampung dipanggang. Satu ekor utuh diletakkan disamping nasi. Ayam hidup warna terserah 1 ekor.

Dukun sunat tidak boleh makan makanan dari hasil selamatan, tetapi syarat rasol, tajin merah putih, bunga, kemenyan harus dipenuhi karena secara otomotis akan melukai Dukun sunat dalam bentuk tiba-tiba pingsang/tidak sadar, bisanya bila terjadi yang demikian Dukun sunat diberi rokok kemudian perlahan-lahan bisa sadar. 
Adapun prosesi sunat yang dilakukan oleh tenaga tradisional pada bayi perempuan adalah sebagai berikut: Bayi tidak ada persiapan khusus. Pisau untuk nyunat disebut "anyi-anyi" alat ini biasanya digunakan untuk memotong padi. Tetapi ini diperoleh turun temurun dalam kondisi sudah tumpul dibungkus plastik. Dukun sunat puasa 4 hari khusus untuk prosedur nyunat sampai hari $\mathrm{H}$, sehingga apabila Dukun sunat sedang haid tidak bisa nyunat. Pembacaan mantra kemudian ditiupkan ke pisau sunat. Pisau sunat 'esonson' dengan diletakkan diatas “mardah pengasapan yang sudah diberi kemenyan selama 5 menit. Tangan dukun sunat diletakkan diatas damar kambang kurang lebih $10 \mathrm{~cm}$ kemudian diusapkan ke muka bayi dengan arah dari atas ke bawah sebanyak 3 kali diakhiri dengan pembacaan mantra. Pembacaan mantra ditiupkan ke dahi. Pembacaan mantra kemudian dukun memegang anyi-anyi. Kaki bayi ditahan oleh asisten dengan cara memegang kedua lutut bayi kearah keluar. Membaca mantra kemudian mengusapkan tangan kanan ke seluruh permukaan vulva dari arah suprapubis ke anus sebanyak 3 kali. Dukun sunat membaca doa kemudian ditiupkan ke pisau kemudian disunatkan dengan cara tangan kiri membuka sambil menahan labia mayora (atau dengan cara memegang kunyit sebesar 1 ruas jari kelingking yang ujungnya dikupas, ujung kunyit diletakkan dibawah klitoris), tangan kanan memegang pisau sunat kemudian digoreskan ke ujung klitoris dengan arah dari atas ke bawah 3 kali, dari kanan ke tengah 3 kali, dari kiri ke tengah 3 kali. Dilakukan sebanyak 2 kali. Tidak ada perawatan khusus sesudah sunat.

Hasil observasi selama sunat terhadap bayi antara lain: bayi tenang, tidak menangis, tidak meringis, tidak mengernyitkan dahi, tidak ada respon terkejut, tidak ada respon berkedip karena terkejut atau sakit, tidak ada respon memejamkan mata, menggerakkan kepala menoleh ke kanan dan ke kiri, menggerakkan kaki fleksi dan ekstensi berulang, dan mengeluarkan suara. Hasil observasi ini menunjukkan bahwa prosesi sunat tidak menimbulkan sensasi nyari. Hasil pemeriksaan inspeksi pada area vagina didapatkan data: tidak ada pengeluaran darah, tidak ada perubahan warna, tidak ada luka gores, tidak menangis saat kencing. Hasil inspeksi juga tidak menunjukkan adanya suatu luka sayat. Hal ini merupakan indikasi bahwa prosedur sunat yang dilakukan tenaga tradisional tidak membuat luka, baik pada labia mayora, labia minora, maupun klitoris.

\section{KESIMPULAN}

a. Sunat pada bayi perempuan yang dilakukan oleh tenaga tradisional dengan menggunakan "anyi-anyi” tumpul tidak melukai klitoris dan tidak ada laporan tentang dampak negatif FGM baik yang ringan maupun yang berat.

b. Tujuan sunat lebih utama mengikuti tradisi dibandingkan dengan tujuan melakukan eksisi yang sesunggunya terhadap klitoris.

\section{UCAPAN TERIMA KASIH}


Terima kasih kepada Direktur Jendral Pendidikan Tinggi Kementerian Riset dan Pendidikan Tinggi RI

\section{DAFTAR PUSTAKA}

Amu, Udeh, Ugochukwu, Madu, dan Nzegwu. 2012. A case of vulval swelling secondary to female circumcision posing a diagnostic dilemma. International journal of surgery case reports. 2012; 3(9): 431-434. Published online 2012 May 24. doi: 10.1016/j.ijscr.2012.03.038. PMCID: PMC3397301.

Bjälkander, Bangura, Leigh, Berggren, Bergström, dan Almroth. 2012. Health complications of female genital mutilation in Sierra Leone. International journal of women's health 4: 321-331. Published online 2012 July 6. doi: 10.2147/IJWH.S32670. PMCID: PMC3410700.

Dalal, Lawoko, Jansson. 2010. Women's attitudes towards discontinuation of female genital mutilation in Egypt. Journal Injury and Violence Research. 2010 January; 2(1): 41-47. doi:10.5249/jivr.v2i1.33 PMCID: PMC3134892

Ezenyeaku, Okeke, Chigbu, Ikeako. 2011. Survey of Women's Opinions on Female Genital Mutilation (FGM) in Southeast Nigeria: Study of Patients Attending Antenatal Clinic. Annal Of Medical \& Health Sciences Research. Jan-Jun; 1(1): 15-20. PMCID: PMC3507097

Gele, Bo, Sundby. 2013. Have we made progress in Somalia after 30 years of interventions? Attitudes toward female circumcision among people in the Hargeisa district. Biomed central research notes. 2013; 6: 122. Published online 2013 March 27. doi: 10.1186/1756-0500-6-122. PMCID: PMC3614471.

Ika. 2007. Sunat Pada Perempuan. http://komunitasbidan.blogspot.com.

Juliansyah. RA. 2009. Sunat perempuan: pro/kontra, tradisi atau agama. duniakeperawatan.wordpress.com.

Martinelli dan Ollé-Goig. 2012. Female genital mutilation in Djibouti. Africa Health Science. December; 12(4): 412-415. PMCID: PMC3598278

Muslihatun. 2010. Pewarisan budaya. http://muslikhatunantropologi.blogspot.com /2010/11/pewarisan-budaya.html

Okwudili dan Chukwudi. 2012. Urinary and Genital Tract Obstruction as a Complication of Female Genital Mutilation: Case Report and Literature 
Review. Journal Surgical Technique case Report. Jan-Jun; 4(1): 64-66. doi: 10.4103/2006-8808.100360PMCID: PMC3461785.

Wikipedia. 2013. Kafir. Wikipedia bahasa Indonesia, ensiklopedia bebas.

Zaharuddin, 2006. Hukum khitan wanita dan bagaimana Rosulullah. http:// zaharuddin.net/fiqh-ibadah/234-hukum-khatan-wanita-bagaimanarasulullah-html 